\title{
Effect of cis-9, trans-11 Conjugated Linoleic Acid (CLA) on the Metabolism Profile of Breast Cancer Cells Determined by ${ }^{1} \mathrm{H}$ HR-MAS NMR Spectroscopy
}

\author{
Roberta M. Maria, ${ }^{\oplus a}$ Wanessa F. Altei, ${ }^{b}$ Napoleão F. Valadares, ${ }^{c}$ Richard C. Garratt, ${ }^{b}$ \\ Adriano D. Andricopulo, ${ }^{b}$ Tiago Venâncio ${ }^{d}$ and Luiz A. Colnago ${ }^{*, a}$ \\ ${ }^{a}$ Embrapa Instrumentação, Rua XV de Novembro 1452, 13560-970 São Carlos-SP, Brazil \\ ${ }^{b}$ Instituto de Física de São Carlos, Universidade de São Paulo, \\ Av. Trabalhador São-carlense 400, 13560-970 São Carlos-SP, Brazil \\ ${ }^{c}$ Laboratório de Biofísica Molecular, Departamento de Biologia Celular, \\ Universidade de Brasília, 70910-900 Brasília-DF, Brazil \\ ${ }^{d}$ Departamento de Química, Centro de Ciências Exatas e de Tecnologia, \\ Universidade Federal de São Carlos, Rodovia Washington Luís, km 235, \\ CP 676, 13565-905 São Carlos-SP, Brazil
}

\begin{abstract}
Conjugated linoleic acid (CLA), a fatty acid found in ruminant food products, has been associated with anticarcinogenic activity. However, its effect on cancer metabolism is unclear. In this paper we evaluated the effects of cis-9, trans-11 CLA on the metabolic profile of MCF-7 and MDA-MB-231 breast cancer cells using high-resolution magic angle spinning (HR-MAS) nuclear magnetic resonance (NMR) spectroscopy. The NMR spectra showed that phosphocholine level, a cancer malignance biomarker, was reduced in both cells treated with CLA, but the reduction was more pronounced in MCF-7 cells. The NMR spectra also showed that CLA has opposite effect on MCF-7 and MDA-MB-231 acetone metabolism. Acetone signal has been observed in the spectra of MDA-MB-231 control cells, but not in the spectra of the cells treated with 50 and $100 \mu \mathrm{M}$ CLA. Conversely, the acetone signal is very small or not observed in the NMR spectra of MCF-7 control cells and in cells treated with $50 \mu \mathrm{M}$ of CLA, but is very strong in the spectra of the cells treated with $100 \mu \mathrm{M}$ of CLA. Therefore, this CLA concentration is causing a ketosis in MCF-7 cells by inducing the use of fatty acids as an energy source or by reducing acetone catabolism. These results indicate that CLA interfere in the metabolism of both cells. However, the strongest effect has been observed on the metabolism of MCF-7 cells cultivated in the presence of $100 \mu \mathrm{M}$ CLA. Therefore, CLA could be a potential anticarcinogenic drug, especially for cells with positive estrogen receptor, such as MCF-7.
\end{abstract}

Keywords: conjugated linoleic acid, CLA, metabolomics, breast cancer, nuclear magnetic resonance

\section{Introduction}

Conjugated linoleic acid (CLA) is a class of fatty acids that are typically found in meat and dairy products from ruminants (cattle, goats, and sheep). ${ }^{1}$ It has gained special attention because of its potential human health benefits, which include an anticarcinogenic activity. ${ }^{2}$ CLA is a group of positional and geometric isomers of linoleic acid (cis-9, cis-12 octadecadienoic acid). There are many CLA isomers, but cis-9, trans-11 represents $75-90 \%$ of the total CLA in

*e-mail: luiz.colnago@embrapa.br ruminant fat. ${ }^{3}$ CLA is classified by the United States Food and Drug Administration (FDA) agency to be generally recognized as safe (GRAS) as disclosed in notice number GRN 000232. ${ }^{4}$

Most studies on the anticarcinogenic activity of CLA rely upon gene regulation (p53,p21 WAF1/CIP1, bax, and bcl-Xs)..$^{5-7}$ Recent studies have shown that CLA interferes on the expression of major oncogenes involved in programmed cell death (apoptosis) ${ }^{3,5}$ or on the regulation of protein kinase $\mathrm{C}$ isoforms in benign and malignant cells. ${ }^{8}$

In this work, the anticarcinogenic effects of cis-9, trans-11 CLA in intact breast cancer (BC) cells metabolism 
were investigated using high-resolution magic angle spinning ( ${ }^{1} \mathrm{H}$ HR-MAS) nuclear magnetic resonance (NMR) technique. HR-MAS NMR spectroscopy has been successfully used to study the metabolic profile of intact ex situ tissues from different types of cancer, ${ }^{9}$ especially BC. ${ }^{10} \mathrm{BC}$ is the most common cancer and the one that has the highest incidence and mortality among all malignancies in women. ${ }^{11,12}$

The first study on the metabolic profile of BC tissue using HR-MAS was performed in 1998 by Cheng et al..$^{13}$ Since then, several HR-MAS studies have been performed in BC tissues in order to correlate NMR data with clinical observations as well as to differentiate tumor subclasses, to mention a few..$^{14,15}$ Recently, Haukaas et al..$^{10}$ reviewed the application of HR-MAS in BC and corroborated the potential of such technique in providing important predictive and prognostic information concerning the disease.

\section{Experimental}

\section{Cell culture}

MCF-7 and MDA-MB-231 BC cells are positive and negative estrogen receptors, respectively. The cells were cultivated in $75 \mathrm{~cm}^{2}$ cell culture flasks, in a $\mathrm{CO}_{2}$ incubator at $37{ }^{\circ} \mathrm{C}$. MDA-MB-231 and MCF-7 cells were maintained in L-15 (Leibovitz, Cultilab) and DMEM (Dulbecco's modified Eagle's medium, Cultilab), respectively, both supplemented with $10 \%$ fetal bovine serum (FBS). Cell viability was tested by Trypan Blue exclusion before experiments.

\section{Exposition of MDA-MB-231 and MCF-7 cells to CLA}

To prepare the CLA supplemented media, we made a stock solution of CLA (1 mM) in FBS. This solution was sterile filtered using $0.22 \mu \mathrm{m}$ syringe filters and diluted into the culture media DMEM and L-15 to obtain these supplemented media with 50 and $100 \mu \mathrm{M}$ of CLA. ${ }^{16-19}$ Before experiments, culture media were supplemented with $10 \%$ of FBS. Each cell strain, MDA-MB-231 and MCF-7, were cultivated in three different $75 \mathrm{~cm}^{2}$ culture flasks. Cells were seeded in a density of ca. $1.4 \times 10^{4}$ cells $\mathrm{mL}^{-1}$, and after three days at $37{ }^{\circ} \mathrm{C}$ in $5 \% \mathrm{CO}_{2}$, the culture medium of flasks was replaced by the CLA supplemented media in different concentrations (0,50 and $100 \mu \mathrm{M}$ of CLA). After three days of exposition to CLA, the cells were detached with trypsin, centrifuged, resuspended in deuterated water and re-centrifuged. The pellets of cells were submitted to NMR analysis. This procedure was applied to the three different experimental media in MDA-MB-231 and MCF7 cells, and four replicates of each concentration of CLA were performed to investigate the effect of this substance in tumor cells.

\section{${ }^{1} \mathrm{H}$ HR-MAS NMR analysis}

${ }^{1} \mathrm{H}$ HR-MAS NMR spectroscopy was performed at 9.4 $\mathrm{T}\left(400.21 \mathrm{MHz}\right.$ for $\left.{ }^{1} \mathrm{H}\right)$ and $14.1 \mathrm{~T}(600 \mathrm{MHz}$ for $\left.{ }^{1} \mathrm{H}\right)$ on a DRX 400 Bruker NMR spectrometer and an Avance 600 Bruker NMR spectrometer, respectively. A spinning rate of $5 \mathrm{kHz}$ was used. Sodium trimethylsilyl[2,2,3,3- $\left.{ }^{2} \mathrm{H}_{4}\right]-1$-propionate (TMSP) was used as internal standard. The spectra were acquired with presaturation pulse of $1.5 \mathrm{~s}$, acquisition time of $4.63 \mathrm{~s}$ (32K points), recycle delay of $4 \mathrm{~s}$, and accumulation of 256 transients. In addition, a Carr-Purcell-Meiboom-Gill (CPMG) spin-echo train was used before acquisition by applying 120 cycles separated by $1.2 \mathrm{~ms}$ of echo time. The free induction decay (FID) signal was multiplied by a $1.0-\mathrm{Hz}$ $(0.0025 \mathrm{ppm})$ line-broadening factor as well as a zero filled two-fold for Fourier transform. The Advanced Chemistry Development (ACD) Labs software was used for automatic phase adjustment and baseline correction. Samples were also analyzed using two-dimensional (2D) NMR spectroscopy methods, including COSY (correlation spectroscopy), ${ }^{1} \mathrm{H},{ }^{13} \mathrm{C}$-HSQC (proton-carbon heteronuclear single-quantum correlation spectroscopy), and ${ }^{1} \mathrm{H},{ }^{13} \mathrm{C}-\mathrm{HMBC}$ (proton-carbon heteronuclear multiple bond correlation spectroscopy). Online databases (e.g., Human Metabolome Database (HMDB) and Chenomx) were also suitable for assignments. One-dimensional (1D) ${ }^{1} \mathrm{H}$ HR-MAS spectra were normalized by correcting baseline offset to zero as well as dividing each data point by the sum of all data points. The values were then multiplied by 1000 .

\section{Results}

Figures 1 and 2 show the typical ${ }^{1} \mathrm{H}$ HR-MAS NMR spectra of MDA-MB-231 and MCF-7 BC cells, respectively. These spectra were acquired using CPMG pulse sequence in order to suppress the broad signals of macromolecules and molecular assemblies as well as to highlight the sharp signals of the metabolites. ${ }^{10}$ Figures 1a and 2a present the spectra of CLA-untreated cells (control). Figures $1 b$ and $2 b$ show the spectra of cells treated with $50 \mu \mathrm{M}$ of CLA, while Figures $1 \mathrm{c}$ and $2 \mathrm{c}$ display the spectra of those treated with $100 \mu \mathrm{M}$ of CLA. Although the chemical shift ( $\delta$, in ppm) profiles assigned to the metabolites in MDA-MB-231 and MCF-7 cells were similar, the peak areas were different, revealing differences in their concentrations in cells. 


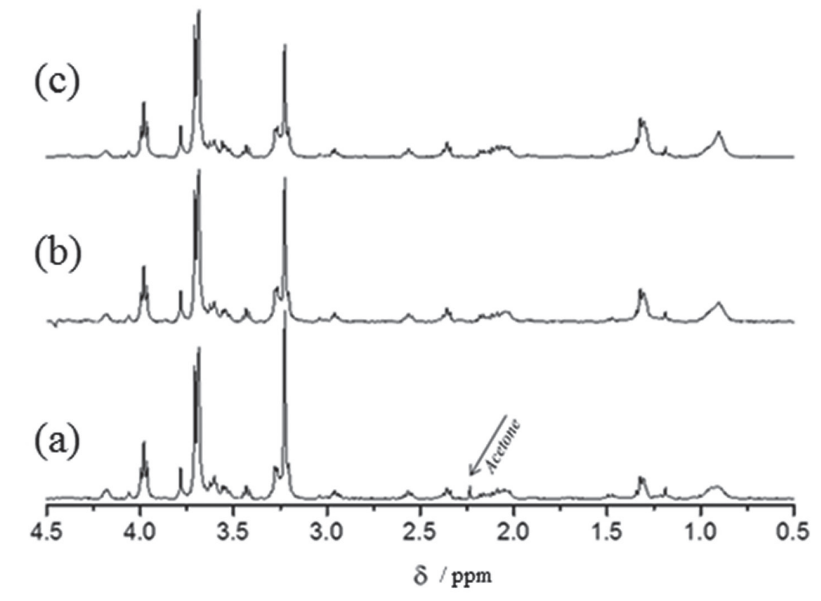

Figure 1. ${ }^{1} \mathrm{H}$ HR-MAS NMR spectra of MDA-MB-231 breast cancer cells. (a) Control cells; (b) cells treated with $50 \mu \mathrm{M}$ or (c) $100 \mu \mathrm{M}$ of CLA. ${ }^{1} \mathrm{H}$ HR-MAS NMR spectra were acquired using CPMG as $\mathrm{T}_{2}$-filtered to remove signals of large molecules with short transverse relaxation times. The arrow indicates the acetone signal in breast cancer cells.

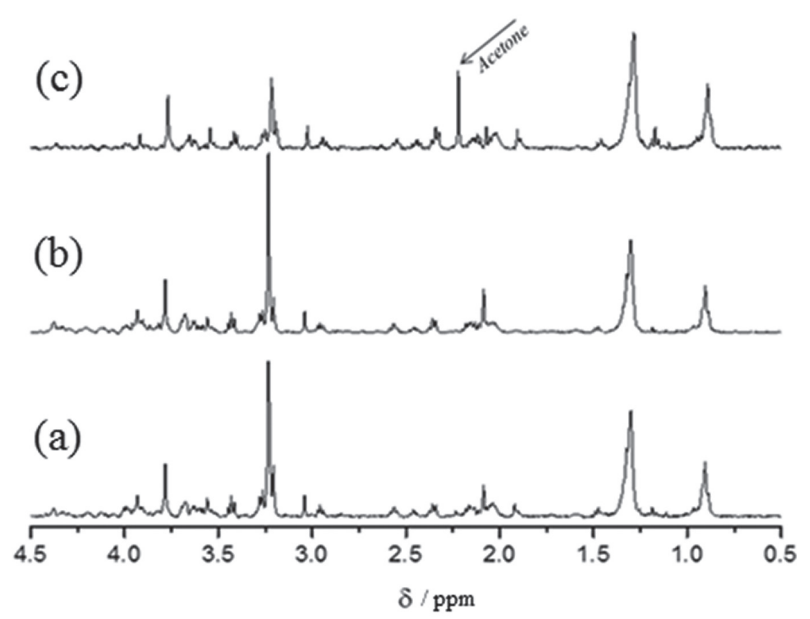

Figure 2. ${ }^{1} \mathrm{H}$ HR-MAS NMR spectra of MCF-7 breast cancer cells. (a) Control cells; (b) cells treated with $50 \mu \mathrm{M}$ or (c) $100 \mu \mathrm{M}$ of CLA. ${ }^{1} \mathrm{H}$ HRMAS NMR spectra were acquired using CPMG as $\mathrm{T}_{2}$-filtered to remove signals of large molecules with short transverse relaxation times. The arrow indicates the acetone signal in breast cancer cells.

The spectra of MCF-7 and MDA-MB-231 cells have been previously assigned elsewhere using 1D NMR database and 2D NMR experiments..$^{20,21}$ The major components of these cells were lactate quartet at $\delta 4.11$ and doublet at $\delta 1.32$, threonine at $\delta 1.33$, alanine at $\delta 1.47$, acetate singlet at $\delta 1.91$, acetone singlet at $\delta 2.2$, choline at $\delta 3.20$, phosphocholine at $\delta 3.22$, taurine at $\delta 3.25$ and 3.42 , and guanidinoacetate at $\delta 3.78$.

The non-overlapped peak of each metabolite was used to calculate its relative intensity (in triplicate) in relation to the total area of each normalized spectrum. The intensities of some signals were significantly different in both control $\mathrm{BC}$ cell lines. The levels of threonine $(2.06 \pm 0.1)$, alanine $(0.30 \pm 0.04)$, acetate $(0.26 \pm 0.02)$, creatine $(0.45 \pm 0.09)$, and taurine $(0.77 \pm 0.10)$ were found to be higher in control
MCF-7 cells (Figure 2a). On the other hand, acetone $(1.56 \pm 1.05)$, choline $(1.11 \pm 0.30)$, and phosphocholine (11.22 \pm 1.30$)$ contents were high in control MDA-MB-231 cells (Figure 1a). Lactate content was similar in both cells (1.67 \pm 0.30 and $1.69 \pm 0.40$ in MCF-7 and MDA-MB-231 control cells, respectively). The differences observed between the metabolic profiles of non-tumor cells and those of MCF-7 and MDA-MB-231 have been addressed previously. ${ }^{22}$

The main difference observed in MDA-MB-231 cells treated with $100 \mu \mathrm{M}$ of CLA was the reduction of the peak assigned to phosphocholine ( $\delta 3.23 \mathrm{ppm})$ by $33.5 \pm 12.5 \%$ (Figure 1c) when compared to control cells (Figure 1a). Similarly, the intensity of phosphocholine in MCF-7 cells decreased by $32.5 \pm 19.1 \%$ after treatment with $100 \mu \mathrm{M}$ of CLA (Figure 2c) when compared to control cells (Figure 2a).

Additionally, we observed a difference in the intensity of the signal assigned to acetone, which were in low concentration in MDA-MB-231 control cells (Figure 1a) and were not observed after treatments with 50 and $100 \mu \mathrm{M}$ of CLA (Figures $1 \mathrm{~b}$ and 1c, respectively). The NMR spectra of MCF-7 control and treated cells $(50 \mu \mathrm{M}$ of CLA) showed very small acetone signal (Figures 2a and $2 \mathrm{~b})$. Conversely, the spectra of cells treated with $100 \mu \mathrm{M}$ of CLA shows a strong acetone signal (Figure 2c), more than an order of magnitude increases when compared to control MCF-7 cells. The intensities of the other metabolites did not change significantly when MCF-7 and MDA-MB-231 cells were exposed to $100 \mu \mathrm{M}$ of CLA (Figures 1c and 2c).

\section{Discussion}

The reduction of the level of phosphocholine, biomarker of malignance, when both MCF-7 and MDA-MB-231 BC cells were treated with $100 \mu \mathrm{M}$ of CLA, demonstrates the influence of this fatty acid on the metabolism of membrane compounds that play a crucial role in cancer cell growth. The reduction in phosphocholine level was more pronounced in MCF-7 cells indicating that these cells might be more susceptible to CLA.

Reduced phosphocholine levels were also observed in these BC cells upon treatment with commercial chemotherapy drugs, such as tamoxifen, cisplatin, and doxorubicin. ${ }^{20,21}$ However, CLA showed minor influence on other metabolites when contrasted with commercial drugs, indicating that CLA may cause fewer side effects even when used at much higher concentrations.

CLA also affects the acetone metabolism in both BC cells, but in opposite direction. It reduces the concentration of acetone in MDA-MB-231 cells to an undetected level. As 
this cell line is more invasive than MCF-7 cells, this might indicate that CLA is reducing the MDA-MB-231 activity and the cells are not using fatty acid as energy source, reducing acetone biosynthesis, even in absence of glucose.

Conversely, when the MCF-7 cells were treated with $100 \mu \mathrm{M}$ of CLA they present large amount of acetone indicating an increase of acetone synthesis or reduction in acetone catabolism, causing ketosis. Ketosis is a process that normally happens in glucose-depleted cells that have to use other energy source such as fatty acids. ${ }^{23}$ Consequently, the use of fatty acid as energy source can reduce the proliferation and death of cells. ${ }^{23}$ This hypothesis agrees with O'Shea et al. ${ }^{23}$ that associated the cytotoxic effect of CLA on MCF-7 cells to the extensive lipid peroxidation.

Another hypothesis for the high acetone content in MCF-7 cells treated with $100 \mu \mathrm{M}$ of CLA could be related to the degradation of acetone by the cytochrome P450 (CYP), especially isoenzyme CYP2E1. ${ }^{24}$ This enzyme is involved in the degradation of small molecules, including acetone, and have been linked with inflammatory reaction and carcinogenesis in different tissues, suggesting that CYP2E1 may be involved in tumor growth..$^{24,25}$

Clinical studies indicate the existence of a higher expression of CYP2E1 in breast cancer compared to normal tissue, and that activity of this isoenzyme is in agreement with the substrate (small molecules) metabolized. ${ }^{24}$ It was also reported that CYP2E1 is expressed in liver, but also in other tissues such as breast tissue..$^{25}$ It was performed an ectopic expression of CYP2E1 in breast cancer cells with different substrates, including ethanol, indicating that CYP2E1 plays a pivotal role in mammary carcinogenesis. ${ }^{25}$ However, the acetone metabolism by CYP2E1 in breast cancer cells has not been reported in literature earlier.

Therefore, the acetone signal can be associated to fatty acids $\beta$-oxidation process or to the reduction of CYP2E1 expression or simultaneous to both processes, indicating potential CLA anticarcinogenic mechanisms in MCF-7 cells.

\section{Conclusions}

The results corroborate that ${ }^{1} \mathrm{H}$ HR-MAS NMR spectroscopy is an important tool to analyze and discriminate the metabolic profiles of intact cancer cells treated with "potential anticarcinogenic" compounds such as CLA. The NMR spectra demonstrated that CLA is a potential anticarcinogenic compound, evidenced by the significant reduction on phosphocholine level, a malignance biomarker. The NMR spectra also were able to show that CLA affects the acetone metabolism, reducing its concentration in MDA-MB-231 cells and increasing its concentration in MCF-7 cells treated with $100 \mu \mathrm{M}$ CLA.

These NMR results indicate that the strongest CLA effect was observed on the metabolism of MCF-7 cells cultivated in the presence of $100 \mu \mathrm{M}$ CLA. Therefore, CLA could be a potential anticarcinogenic compound, especially for BC cells with positive estrogen receptor, such as MCF-7.

\section{Acknowledgments}

The authors would like to acknowledge FAPESP (grants No. 2009/17846-4 and 2013/05128-5) and CNPq (Brazilian Agencies) for the financial support provided to this research.

\section{References}

1. Parodi, P. W.; J. Nutr. 1997, 127, 1055.

2. Aydin, R.; Turk. J. Vet. Anim. Sci. 2005, 29, 189.

3. Belury, M. A.; J. Nutr. 2002, 132, 2995.

4. Kim, J. H.; Kim, Y.; Kim, Y. J.; Park, Y. ; Annu. Rev. Food Sci. Technol. 2016, 7, 221.

5. Kemp, M. Q.; Jeffy, B. D.; Romagnolo, D. F.; J. Nutr. 2003, 11, 3670.

6. Moon, H. S.; Lee, H. G.; Seo, J. H.; Chung, C. S.; Kim, T. G.; Kim, I. Y.; Lim, K. W.; Seo, S. J.; Choi, Y. J.; Cho, C. S.; Biophysics 2006, 456, 19.

7. El Roz, A.; Bard, J. M.; Huvelin, J. M.; Nazih, H.; Prostaglandins, Leukotrienes Essent. Fatty Acids 2013, 88, 265.

8. Wahle, K. W. J.; Heys, S. D.; Prostaglandins Leukotrienes Essent. Fatty Acids 2002, 67, 183.

9. Wang, A. S.; Lodi, A.; Rivera, L. B.; Garcia, J. L.; Firpo, M. A.; Mulvihill, S. J.; Tempero, M. A.; Berger, G.; Ronen, S. M.; NMR Biomed. 2014, 27, 1361.

10. Haukaas, T. H.; Euceda, L. R.; Giskeodegard, G. F.; Bathen, T. F.; Metabolites 2017, 7, 18.

11. Ferlay, J.; Soerjomataram, I.; Dikshit, R.; Eser, S.; Mathers, C.; Rebelo, M.; Parkin, D. M.; Forman, D.; Bray, F.; Int. J. Cancer 2015, 136, 359.

12. Sitter, B.; Bathen, T. F.; Tessem, M. B.; Gribbestad, I. S.; Prog. Nucl. Magn. Reson. Spectrosc. 2009, 54, 239.

13. Cheng, L. L.; Chang, I. W.; Smith, B. L.; Gonzalez, R. G.; J. Magn. Reson. 1998, 135, 194.

14. Sitter, B.; Lundgren, S.; Bathen, T. F.; Halgunset, J.; Fjosne, H. E.; Gribbestad, I. S.; NMR Biomed. 2006, 19, 30.

15. Sitter, B.; Sonnewald, U.; Spraul, M.; Fjösne, H. E.; Gribbestad, I. S.; NMR Biomed. 2002, 15, 327.

16. Angeluci, C.; Iacopino, F.; Lama, G.; Zelano, G.; Gianesini, G.; Sica, G.; Bono, A. V.; Anticancer Res. 2005, 25, 3937.

17. Miglietta, A.; Bozzo, F.; Bocca, C.; Gabriel, L.; Trombetta, A.; Belotti, S.; Canuto, R. A.; Cancer Lett. 2006, 234, 149. 
18. Hsu, Y.; Ip, M. M.; Cell. Signalling 2011, 23, 2013.

19. Najbjerg, H.; Young, J. F.; Bertram, H. C.; J. Agric. Food Chem. 2011, 59, 8994.

20. Maria, R. M.; Altei, W. F.; Selistre-de-Araújo, H. S.; Colnago, L. A.; Biochemistry 2017, 56, 2219.

21. Maria, R. M.; Altei, W. F.; Selistre-de-Araújo, H. S.; Colnago, L. A.; J. Pharm. Biomed. Anal. 2017, 146, 324.

22. Maria, R. M.; Altei, W. F.; Andricopulo, A. D.; Becceneri, A. B.; Cominetti, M. R.; Venâncio, T.; Colnago, L. A.; Anal. Biochem. 2015, 488, 14.
23. O’Shea, M.; Stanton, C.; Devery, R.; Anticancer Res. 1999, 19, 1953.

24. Porubsky, P. R.; Meneely, K. M.; Scott, E. E.; J. Biol. Chem. 2008, 283, 33698.

25. Leung, T.; Rajendran, R.; Singh, S.; Garva, R.; Krstic, D. M.; Demonacos, D.; Breast Cancer Res. 2013, 15, 107.

Submitted: July 24, 2018 Published online: October 8, 2018 